\title{
Study of functional properties of probiotic and prebiotic on quality Characteristics
} of mango juice

\author{
Heba Y. Nasef \\ Nutri. \& Food Sci. Dept., Faculty of Home Economics, Helwan University, Egypt \\ E-mail:hobanasif91@yahoo.com
}

G.A. Ibrahim

Dairy Science Dept., Food Industry and Nutrition Research Division, National Research Centre, 33 El Buhouth St., 12622 Dokki, Giza, Egypt. E-mail: gamalwahab2015@gmail.com

\begin{abstract}
Abd El-Aziz N. Shehata
Dairy Science Dept., Food Industry and Nutrition Research Division, National Research Centre, 33 El Buhouth St., 12622 Dokki, Giza, Egypt. E-mail: zanadir666@gmail.com.
\end{abstract}

\author{
Eman F. Mohamed
}

Nutri. \& Food Sci. Dept., Faculty of Home Economics, Helwan University, Egypt

E-mail:eeman.ali3000@gmail.com

\author{
Ahmed A. Farrag \\ Nutri. \& Food Sci. Dept., Faculty of Home Economics, Helwan University, Egypt \\ E-mail:Aelatawy@yahoo.com
}

\begin{abstract}
Received: 30 April 2020 / Accepted 15 June 2020 / Publication date: 15 July 2020
\end{abstract}
\begin{abstract}
Recently, there has been much scientific focus on the importance of functional foods and nutraceuticals which contributes for maintaining good health and reducing the risk of noncommunicable diseases remove. So, this study was carried out to investigate the functional properties of probiotic (Lactobacillus rhamnosus, Bifidobacterium breve 2\%), prebiotic (inulin- 2\%) and synbiotic on quality attributes of mango juice $(370 \mathrm{ml})$ during storage period $(1,2$ and 3 weeks) at refrigeration temperature $\left(2-6{ }^{\circ} \mathrm{C}\right)$. Microbiological, chemical, physical analyses and sensory properties were investigated. Four treatments were studied. Fresh mango juice was taken immediately after processing, $\mathrm{T}_{1}$ Mango juice $+L b$. rhamnosus + inulin; $\mathrm{T}_{2}$ Mango juice $+L b$. rhamnosus without inulin; $\mathrm{T}_{3}$ Mango juice + Bif.breve + inulin and $\mathrm{T}_{4}$ Mango juice + Bif.breve without inulin. In addition to control sample (mango juice only). Objective and organoleptic evaluations were carried out to indicate the acceptability of the final products. According to sensory evaluation, Bif.breve + inulin $\left(\mathrm{T}_{3}\right)$ and Bif.breve without inulin $\left(\mathrm{T}_{4}\right)$ samples had the lowest scores for sensory characteristics (taste and overall acceptability) while $\mathrm{T}_{1}$ Mango juice $+L b$. rhamnosus + inulin, $\mathrm{T}_{2}$ Mango juice $+L b$. rhamnosus without inulin had a highest scores. Total sugars (reducing sugars and non-reducing sugars), Vitamin $\mathrm{C}, \mathrm{pH}$, acidity, Total soluble solid, Viscosity and Color of the products were evaluated. All treatments achieved a mean viable count of at least $10^{7} \mathrm{CFU} / \mathrm{ml}$ during storage period. It could be concluded that the probiotic bacteria grew well in all treatments and were capable of surviving and maintaining high viability and enhancing functional properties in the all treatments during storage period without any changes in quality attributes of fruit juices. Therefore, this study indicated a potential for probiotic fruit juices as a valid alternative to dairy based probiotic products. High numerous health benefits of inulin, when combined with the health benefits of probiotic bacteria, could lead to the development of commercial beverages with high health and nutritional values. So food industries should be encourage use probiotic and prebiotic in several products to achieve health benefits of them.
\end{abstract}

Keywords: functional foods, fruit juices, probiotic, prebiotic, synbiotic, inulin, Lactobacillus rhamnosus, Bifidobacterium breve.

Corresponding Author: Abd El-Aziz N.Shehata, Bread and Pasta. Dep., Food Tech. Res. Inst., Agric. Res. Center, Egypt. E-mail: elgendy_nma@yahoo.com 


\section{Introduction}

Functional foods are defined as foods that, in addition to their basic nutrients, contain biologically active components, in adequate amounts, that can have a positive impact on the health of the consumer (Prado et al., 2008). Recently, there has been much scientific focus on the importance of functional foods and nutraceuticals which contribute for maintaining good health and reducing the risk of noncommunicable diseases (Yildiz and Ozcan, 2019).

Well-recognized examples of functional foods are those containing bioactive compounds like dietary fibers, oligosaccharides, vitamins, minerals and active "friendly" bacteria, called probiotics that promote the equilibrium of intestinal microflora (Shah and Prajapati, 2013).

In the last years, consumers increasingly concerned about foods that provide the conventional nutrients and present suitable physicochemical and sensory characteristics, but also improvements on the physical and mental well-being and reduction of the risk of diseases (Kaur and Singh, 2017). Which can be achieved through providing these traits is to add probiotic cultures and prebiotic fibers to the food (Nematollahi et al., 2016).

Widely adopted definition states probiotics as "live microorganisms which when administered in adequate amounts confer a health benefit on the host by improving its intestinal microbial balance (Nadelman et al. 2018 ; Hossain et al. 2019). A food product is considered a probiotic if a minimum of $10^{6} \mathrm{CFU} / \mathrm{mL}$ (colony forming units per $\mathrm{mL}$ ) is reached (Bansal et al., 2016).

Mangos contain the phytochemicals phenolic acid, carotenoids and Gallo tannins (BurtonFreeman et al., 2017). Phenolic acid and carotenoids have been associated with antioxidant activity which is important in extending the shelf life. However, mango antioxidant activity can be affected by the cold storage Fazilah et al. (2018). Phytochemicals have also been reported to improve the viability of gut bacteria and their adhesion to intestinal epithelial cells (Parkar et al., 2013).

Numerous bacteria are considered probiotic, Lactobacillus and Bifido bacterium are the main groups of bacteria used in foods, as they have a historically long and safe use and are identified as GRAS (generally recognized as safe); in addition, they are the dominant inhabitants in the human intestines (Champagne et al., 2018). Studies have been carried out to provide the evidence related to the health benefits of probiotics on gastrointestinal infections, antimicrobial activity, improvement in lactose metabolism, reduction in serum cholesterol, immune system stimulation, antimutagenic properties, anticarcinogenic properties and anti-diarrheal properties, by addition of selected strains to food products (Joseph, 2018).

There are two more essential terms to know, prebiotics and synbiotic. Probiotic viability is directly related to the presence of substrates on fermentation and on metabolic function development. Such substrates called prebiotics, which are defined as the indigestible food ingredients that promote the growth or activity of beneficial bacteria, thereby benefiting the host (Gibson et al., 2017). Generally, the most common prebiotics are soluble Fibres such as inulin (Fazilah et al., 2018). Synbiotics are combinations of probiotics and prebiotics that are designed to improve the survival of the ingested microorganisms and their colonization of the intestinal tract (Wasilewski et al., 2015).

Inulin is a dietary fiber, is not broken down by gut digestive enzymes and may be substituted for fats and sugars without affecting the texture of foods, leading to products with a more balanced nutritional composition (Al-Sheraji et al., 2013). Inulin is used as a low-calorie sweetener, increase viscosity and improve organoleptic attributes in the food industry (Srisuvor et al., 2013).

Inulin has a prebiotic effect because it is fermented by bifidobacteria in the colon, increases the probiotic activity (Lactobacillus and Bifidobacteria) that is noted as a Bifidogenic effect (Shoaib et al., 2016).

The increasing health concerns of lactose intolerance, milk protein allergy, high cholesterol content and high amounts of saturated fatty acids of dairy based foods are resulting in a shift towards non-dairy foods such as probiotic fermented cereals, fruits and vegetables juices (Vijaya Kumar et al., 2013). Over the last ten years, more than 500 new probiotic food and beverages have entered the marketplace (Ramos et al., 2018). Recently, there appears to be an increased interest by food manufacturers in the production of functional fruit. These beverages are relatively simple to produce, have increased consumer acceptance, and the beverages are perceived as healthy and refreshing which conform to current food trends (Islam et al., 2018).

Fruit juices offer several advantages they are a rich source of nutrients and contain sugars to support the growth of probiotics. The addition of fruit juice and pulps to probiotic products appears 
promising in improving probiotic viability, though results are seen to differ depending on the fruit and strain of bacteria used (Ding and Shah, 2008 ; Sarao and Arora, 2017). They also have a good refreshing taste profile and a choice for people of all age groups. One more advantage is that these juices stay very less time in the stomach and thus the probiotic species spend very less time to the harsh acidic environment of the stomach (Anekella and Orsat, 2013).

The objective of the present study was to determine functional properties of probiotic, prebiotic and synbiotic on quality attribute of mango juice.

\section{Materials and Methods}

\section{Materials:}

1.1. Mango fruits were obtained from local markets, Cairo, Egypt.

1.2. Probiotic strains (Lactobacillus rhamnosus NRRL B-442 and Bifidobacterium breve ATCC 17500) were obtained from Dairy Microbiological Lab., Dairy Science Dep., Food Industries and Nutrition Research Division, National Research Center, Dokki, Giza, Egypt.

\subsection{Chemicals:}

Inulin was purchased from The Searle Company Limited (SEARLE), England; MRS was supplemented by SRL Co., India; Malt Extract Agar was provided by Oxoid, England; MaCconkey broth was provided from LAB m, UK. All microbiological media were recommended by American Public Health Association, (1976) and FDA, (2002), and further prepared according to the proper procedures of manufacturers. Chemicals used for proximal determination was purchased from Chemicals Co., in Egypt.

\section{2- Methods:}

Flow chart for preparation of probiotic fruit juice

Preparation of raw materials (mango) $\rightarrow$ washed $\rightarrow$ skins and seeds removed ground pasteurization at $80^{\circ} \mathrm{C}$ for 15 min and immediately cold at $4{ }^{\circ} \mathrm{C}$

$\rightarrow$ To prevent contamination (critical point)

Juice mixed with inulin extraction $2 \%+$ strain of probiotic

Mixture kept at temp $\left(2-6^{\circ} \mathrm{C}\right)$.

\subsection{Preparation of raw materials:}

Mango was washed in tap water and skins and seeds were removed with a sharp knife and the pulp was cut into small pieces, after that it was grounded without any added sugars then pasteurized at $80^{\circ} \mathrm{C}$ for $15 \mathrm{~min}$ and immediately cold at $4^{\circ} \mathrm{C}$ (Vieira and Silva, 2014).

\subsection{Probiotic Culture Preparation:}

All strains of Lactobacillus rhamnosus and Bifidobacterium breve which suspended in MRS broth were inoculated $(2 \% \mathrm{w} / \mathrm{v})$ into reconstituted skim and anaerobically incubated at $37{ }^{\circ} \mathrm{C}$ for $24 \mathrm{~h}$. After the formation of good coagula that contained $10^{6} \mathrm{cfu} / \mathrm{g}$, the cultures were transferred to a refrigerator at $4{ }^{\circ} \mathrm{C}$, and became ready for use.

The steps for overall treatments of Mango samples preparation:-

\section{Control sample (370 ml ) Mango juice only}

( $\left.\mathbf{T}_{1}\right)$ Mango juice $(370 \mathrm{ml})+2 \%$ Lactobacillus rhamnosus $(7.4 \mathrm{ml})+$ inulin $2 \%(17 \mathrm{~g})$.

( $\left.\mathbf{T}_{2}\right)$ Mango juice $(370 \mathrm{ml})+2 \%$ Lactobacillus rhamnosus $(7.4 \mathrm{ml})$ without inulin.

( $\left.\mathbf{T}_{3}\right)$ Mango juice $(370 \mathrm{ml})+2 \%$ Bifido bacterium breve $(7.4 \mathrm{ml})+$ inulin $2 \%(17 \mathrm{~g})$.

( $\left.\mathbf{T}_{4}\right)$ Mango juice $(370 \mathrm{ml})+2 \%$ Bifido bacterium breve $(7.4 \mathrm{ml})$ without inulin. 


\section{Microbiological Analysis:}

The microbiological analysis of different types of collected fruit samples (Mango) under this investigation were carried out including the determination of total bacterial count (TBC), yeasts and molds counts according to the methods recommended in the APHA (1976).

\subsection{Total bacterial count:-}

The total bacterial count was performed using the plate count agar medium as recommended by (APHA, 1976; FDA, 2002).

\subsection{Enumeration of Lactobacilli:-}

Enumeration of Lactobacillus spp. from all fruit juice samples was carried out during storage period ( 0 times, 1 week, 2 weeks, and 3 weeks). Serial dilutions and subsequent plating were used to determine microbial counts of Lactobacillus spp.

\subsection{Enumeration of Bifidobacterium breve:-}

Bifidobacterium breve was counted according to Blanchette et al. (1996) using modified MRS agar (Oxoid) supplemented with $0.05 \%$ L. cysteine-HCL (analytical grad). Plates were incubated at $37^{\circ} \mathrm{C}$ for $48 \mathrm{hrs}$. In both cases plates were incubated under anaerobic environment (BBL Gas, Pak, Becton, Dickinson, Cockeysville MA, USA).

\subsection{Enumeration of coliforms group:-}

Coliform counts were enumerated on MacConkey broth (WHO, 1963). The method was described by El-Hadedy and Abu El-Nour, (2012).

\subsection{Enumeration of molds and yeasts:-}

Molds and yeasts were determined using malt extract agar Galloway and Burgess, (1952).

\section{Objective evaluation include:}

\subsection{Chemical Examination:}

\subsubsection{Determination of total sugars:}

The total, reducing and non-reducing sugars in fruit juices under investigation were determined by the official Lane-Eynone titrimetric method as described in AOAC (2005).

\subsubsection{Determination of ascorbic acid:}

Ascorbic acid content was estimated according to AOAC (2005) using 2, 6 dichlorophenolindophenols by titration method. Result was expressed as mg ascorbic acid per $100 \mathrm{ml}$ samples.

\subsection{Physico chemical analysis:-}

\subsubsection{Determination of $\mathrm{pH}$ values:}

The $\mathrm{pH}$ value of all fruit juice samples were measured separately by digital $\mathrm{PH}$ meter (model 3505- JENWAY - UK) after (0 times, 1 week, 2 week, 3 week) at $25^{\circ} \mathrm{C}$ as described in AOAC (2005).

\subsubsection{Determination of total titratable acidity:}

Total titratable acidity was measured as mentioned in the official method of the AOAC, (2005). It was expressed as citric acid or malic acid using sodium hydroxide N/10 and phynol phythaline as indictor to get $\mathrm{pH}$.

\subsubsection{Determination of total soluble solids:}

Total soluble solids (T.S.S) were determined by using a refractometer, Carl Ziess, Jena (Germany) at $20^{\circ} \mathrm{C}$. A correction was made for different temperatures and the results were reported as ${ }^{\circ} \mathrm{Brix}$ at $20^{\circ} \mathrm{C}$.according to the method described by the AOAC (2005). 


\subsection{Physical properties:-}

\subsubsection{Viscosity:-}

Viscosity was measured in fruit juice samples at $7^{\circ} \mathrm{C}$ using a Brookfield digital viscosity (Model DV- II+VISCOMETER, Spindle-00). The speed was set from 3 to $50 \mathrm{rpm}$. Three reading, 30s apart, were recorded for each sample.

\subsubsection{Color analysis:-}

The color of Mango juice samples after cold storage period (7days, 2 weeks and 3 weeks) was measured according to Hunter (1975), spectro-colorimeter (Tristimulus Color Machine) with CIE lab color scale (Hunter, Lab Scan XE, Germany) calibrated with a while standard tile of Hunter Lab color standard (LXNO. 16379): $X=77.26, Y=81.94$ and $Z=88.14\left(L^{*}=92.71 ; a^{*}=-0.89 ; b^{*}=-0.18\right)$ where $\mathrm{L}^{*}=$ Lightness, $\mathrm{a}^{*}=$ redness, $\mathrm{b}^{*}=$ yellowness), using Hunter-scot field's equation.

Subscript ("O": hue) indicates color of the control, hue angle (tan-1 b/a) and saturation index $[\sqrt{a 2+b 2}]$ will also calculate.

\section{Sensory evaluation:}

Sensory evaluation was carried on for different product's characteristics: color, odor, taste, flavor, viscosity, and overall acceptability. Organoleptic evaluation was carried out by 15 well trained from (National Research Center - Cairo -Egypt) Using a score sheet. All characteristics were evaluated from 1-5 degree (1 represents very poor and 5 represents very good general acceptability) according to Penfield and Campbell, (1990).

\section{Statistical analysis:}

The statistical analysis will carry out using SAS statistical software; the results were expressed as (mean $\pm \mathrm{SD}$ ). Data were analyzed by one way analysis of variance (ANOVA). The differences between means were tested for significance using least significant difference test (LSD) at $(\mathrm{P}<0.05)$ (SPSS, 1986).

\section{Results and Discussion}

The presented data shows the state of probiotics in non-dairy fruit juice that supplemented with inulin fibers. Table (1) and Figure (1) present cell count (log cfu/ml) of Lb. rhamnosus in mango juice. Results showed that there was a significant difference $(\mathrm{p}<0.05)$ in $L b$. rhamnosus between $\mathrm{T}_{1}$ (with inulin) and $\mathrm{T}_{2}$ (without inulin) over storage periods. Upon comparing the Lb. rhamnosus viable counts, it was found that in the presence of inulin in $T_{1}$ the growth increased over $T_{2}$ by $0.2 \log \mathrm{cfu}$, $1.1 \log$ cfu and $0.8 \log$ cfu after 1 weeks 2 weeks and 3 weeks respectively.

These distinctions could be attributed to the addition of inulin in $T_{1}$ samples. Although the viability of $L b$. rhamnosus population decreased the viable count of the probiotic mango juice didn't fall below $10^{6} \mathrm{cfu} / \mathrm{ml}$ over storage period.

The enhanced viability of $L b$. rhamnosus is simply attributed to the effective stimulation of inulin, so the count of Lb. rhamnosus in $\mathrm{T}_{1}$ with inulin was higher than the $\mathrm{T}_{2}$ without inulin. These results came in agreement with the recommendations of Ranadheera et al. (2017), who suggested that probiotic count must be maintained at $10^{6}-10^{7} \mathrm{cfu} / \mathrm{mL}$ until the beverage storage period to confer a health benefit to the consumer. The addition of mango juice may provide additional nutrients to support cell synthesis and growth subsequently (Sarao and Arora, 2017).

Also, the total viable count was seen to be slowly increased reaching $8.5 \pm 0.02 \log \mathrm{cfu} / \mathrm{ml}$ in $\mathrm{T}_{1}$ with inulin after 2 weeks until became stable at $6.9 \mathrm{log} \mathrm{cfu} / \mathrm{ml}$ at the end of the $3^{\text {rd }}$ week, while in the absence of inulin the counts of Lb. rhamnosus decrease during the storage period (3 weeks) compared to without inulin. These results confirmed what obtained by Nikmaram et al. (2015), who added inulin fiber to pomegranate juice supplemented with yogurt, and found that the survival of $L b$. casei was increased.

In contrast, there was no detected growth for coliforms or E. coli, even molds and yeasts during the 3 weeks cold storage period for all treatments. This recorded absence of E. coli and fecal coliforms represents clear evidence on efficiency of heat treatment, and the following of the proper 
hygienic procedures during preparation and storage of Mango juice and other additives (Amin et al., 2018).

Table 1: Microbiological examination of probiotic Mango juice with $L b$. rhamnosus during storage period at refrigerator temp. $\left(2-6^{\circ} \mathrm{C}\right)$

\begin{tabular}{|c|c|c|c|c|c|c|c|}
\hline & \multicolumn{6}{|c|}{ Microbial Count $(\log$ CFU/ml) } \\
\hline & & Coliforms Count & E. coli & Lb. rhamnosus & Molds & Yeasts & Total Viable Count \\
\hline \multirow{4}{*}{ T1 } & 0 time & Nil & Negative & $6.9 \pm 0.01$ & Nil & Nil & $4.7 \pm 0.03$ \\
\hline & 1 week & Nil & Negative & $7.0 \pm 0.01$ & Nil & Nil & $7.2 \pm 0.02$ \\
\hline & 2 weeks & Nil & Negative & $8.1 \pm 0.01$ & Nil & Nil & $8.5 \pm 0.02$ \\
\hline & 3 weeks & Nil & Negative & $7.9 \pm 0.01$ & Nil & Nil & $6.9 \pm 0.01$ \\
\hline \multirow{4}{*}{ T2 } & 0 time & Nil & Negative & $6.9 \pm 0.00$ & Nil & Nil & $4.6 \pm 0.05$ \\
\hline & 1 week & Nil & Negative & $6.8 \pm 0.02$ & Nil & Nil & $7.2 \pm 0.03$ \\
\hline & 2 weeks & Nil & Negative & $7.0 \pm 0.00$ & Nil & Nil & $6.5 \pm 0.03$ \\
\hline & 3 weeks & Nil & Negative & $7.1 \pm 0.01$ & Nil & Nil & $7.0 \pm .01$ \\
\hline
\end{tabular}

Data expressed as Mean \pm St. error, $\mathrm{P}<0.05, \mathbf{T}_{1}:$ Lb. rhamnosus +inulin, $\mathbf{T}_{2}:$ Lb. rhamnosus without inulin

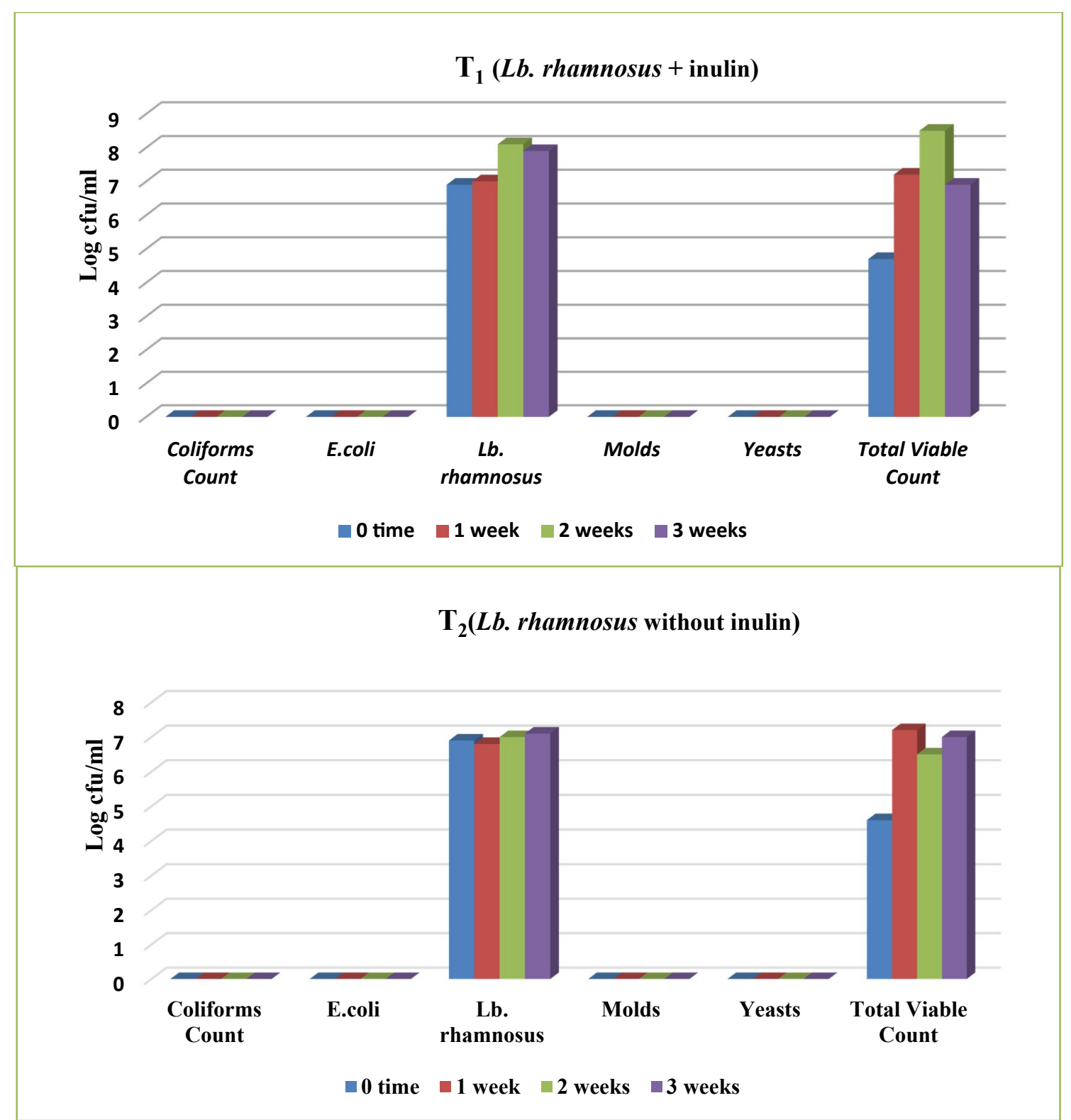

Fig. 1: Microbiological examination of probiotic Mango juice with Lb. rhamnosus during storage period at refrigerator temp. $\left(2-6^{\circ} \mathrm{C}\right)$ 


\section{1- Microbiological Evaluation}

Table (2) and Figure (2) present the count development of Bifidobacterium breve that expressed as $\log \mathrm{cfu} / \mathrm{ml}$ in Mango juice. Results showed that there was a significant difference $(\mathrm{p}<0.05)$ in Bifidobacterium breve count between $\mathrm{T}_{3}$ (with inulin) and $\mathrm{T}_{4}$ (without inulin) over storage periods. Upon comparing Bifidobacterium breve viable counts, it was found that in the presence of inulin in $\mathrm{T}_{3}$, the growth was increased over $\mathrm{T}_{4}$ by $0.1 \log$ cfu, $0.1 \log$ cfu and $0.3 \log$ cfu after 1 week, 2 weeks and 3 weeks respectively. It appears that $L b$. rhamnosus growth was encouraged by the addition of inulin to mango juice more than Bifidobacterium breve. Such results were observed by Önal Darilmaz et al., (2019) who found that the maximal probiotic growth that stimulated by inulin differs from one strain to another. They explained the enhancing effect of this polysaccharide; inulin by the increased level of fructose as a result of partial hydrolysis of inulin by probiotics through Glycolytic pathways as described by Oliveira et al., (2012).

Table 2: Microbiological examination of probiotic Mango juice with Bifidobacterium breve during Storage period at refrigerator temp. (2 -6 o C)

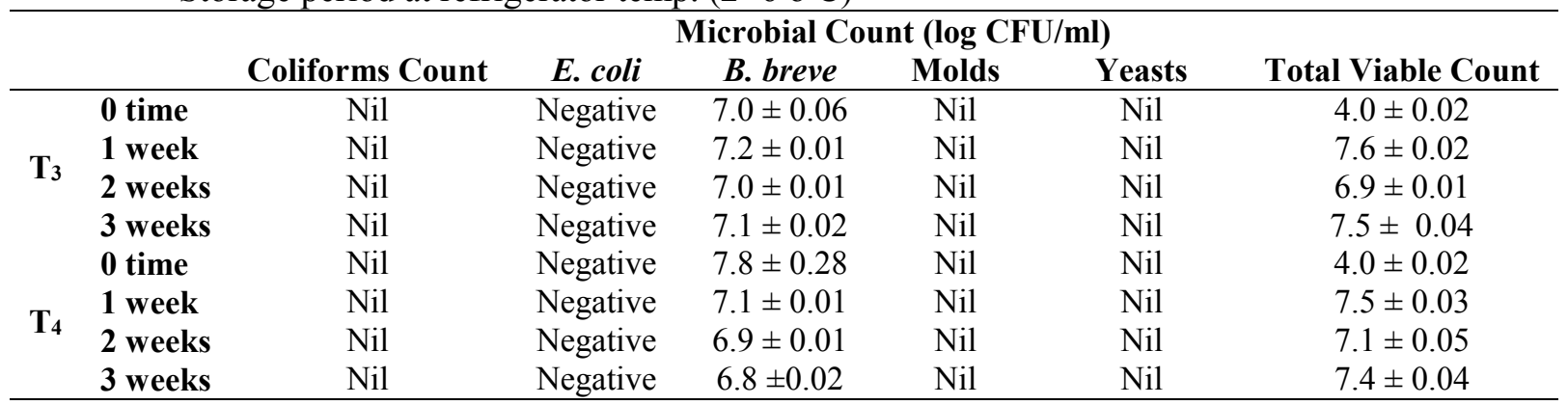

Data expressed as Mean \pm St. error, $\mathrm{P}<0.05, \mathbf{T}_{3}$ : Bif. breve +inulin, $\mathbf{T}_{4}$ : Bif.breve without inulin.

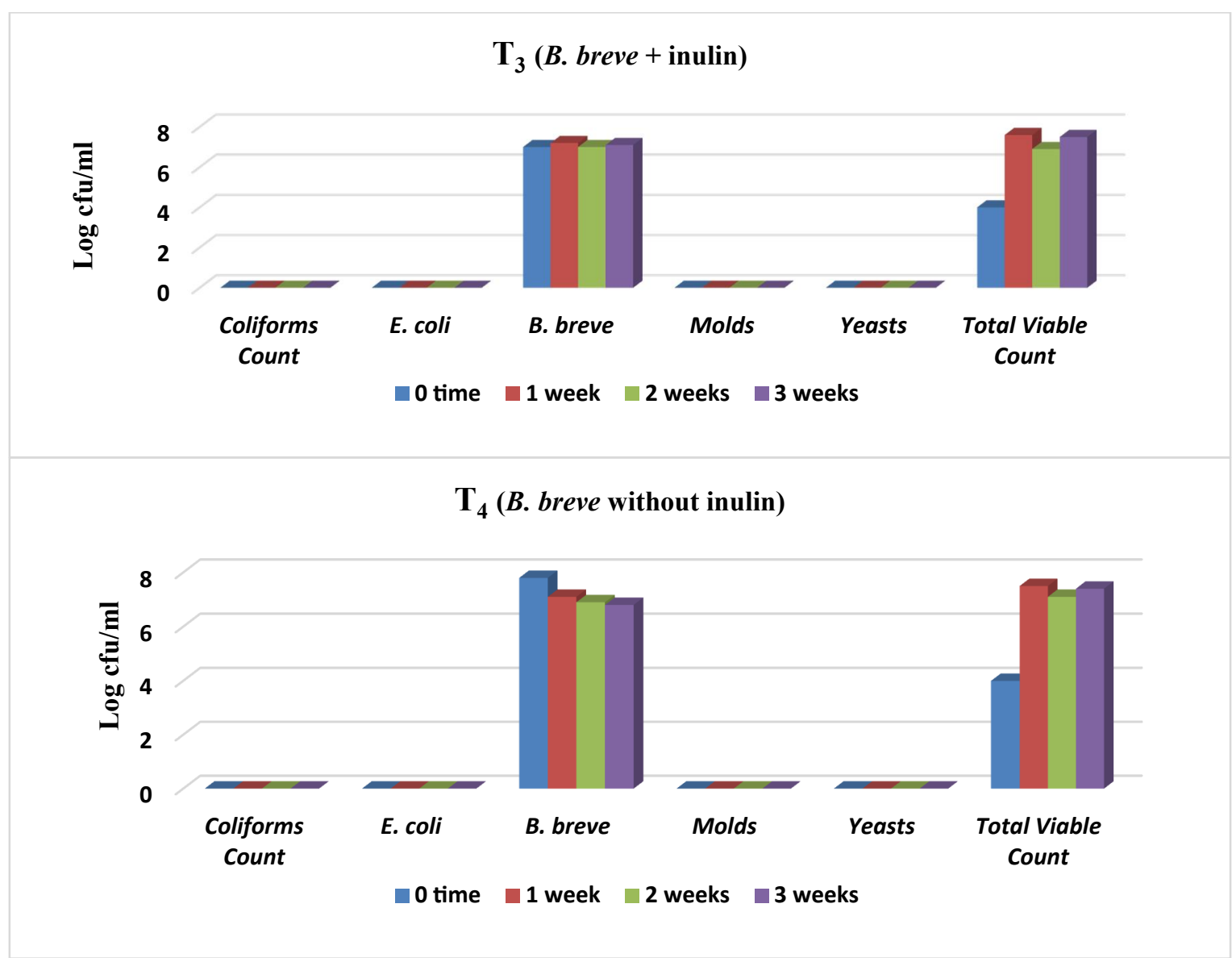

Fig. 2: Microbiological examination of probiotic Mango juice with Bifidobacterium breve during storage at refrigerator temp. $\left(2-6{ }^{\circ} \mathrm{C}\right)$ 
Also, it was observed that the total count in T3 (with inulin) reduced than T4 (without inulin) by $0.1 \log \mathrm{cfu} / \mathrm{ml}$ at the end of 3 weeks of storage period. It appears that released acid, by Bifidobacterium breve in case of $\mathrm{T} 3$, retarded the growth of all flora other than acid-tolerant Bifidobacterium breve. The results revealed that there was no growth of total coliform, E. coli, molds and yeasts in all treatments during storage $(3$ weeks $)$ at refrigerator temperature $\left(2-6^{\circ} \mathrm{C}\right)$

Mangos contain the phytochemicals phenolic acid, carotenoids and Gallo tannins BurtonFreeman et al., (2017). Phenolic acid and carotenoids have been associated with antioxidant activity which is important in extending the shelf life. However, mango antioxidant activity can be affected by the cold storage Fazilah et al. (2018). Phytochemicals have also been reported to improve the viability of gut bacteria and their adhesion to intestinal epithelial cells Parkar et al., (2013).

So, the development of probiotic fruit juices is possible, allowing the consumption of these beneficial microorganisms by people who do not prefer the intake of dairy products. Furthermore, the inclusion of probiotic fruit juices in the market increases the number of available probiotic products to the general population.

\section{2- Objective Evaluation Include :}

\section{1- Chemical Examinations}

\subsection{1- Changes in sugars values:}

Data presented in Fig 3 ( $a, b$ \&c) showed the Changes in sugars values of mango juices treated with or without inulin and two different strains of probiotic during storage ( 0 time (fresh) and after 3 weeks at temp $\left(2-6^{\circ} \mathrm{C}\right)$. From these data it could be observed that the total sugars in fresh mango juice (0 times) ranged from (14.80: 14.81) g/ $100 \mathrm{ml}$ of mango juice. Non- reducing sugars was formed the highest percentage of total sugars. The main values of non-reducing sugars ranged from (12.18: 12.20 $\%$ ), while the reducing sugars recorded 2.61: $2.62 \%$ only.

Data in Fig $3(a, b \& c)$ illustrated that the Changes in sugars values of mango juices after storage 3 weeks, the total sugars were totally decreased especially non- reducing sugars, whereas reducing sugar were increased.

Although the growth of $L b$. rhamnosus and Bif.breve during storage was expected to reduce the concentration of reducing sugars but the value of reducing sugars was increased Figure $3(\mathrm{a}, \mathrm{b} \&$ c). The hydrolysis of inulin into fructose and glucose could have masked the amount of sugars consumed by Lb. rhamnosus and Bif.breve. During storage, our results were in line with findings of Lee et al., (2013) who reported that the decrease in sucrose could be ascribed to the acid and / or enzymatic hydrolysis.

The concentrations of reducing and non-reducing sugars were measured to determine the consumption of glucose or fructose by Lb. rhamnosus and Bif.breve or degradation of inulin to fructose. In this study, inulin was added into mango juice, are as a polymer of fructose molecules with glucose molecules attached at the terminal end. During storage, these molecules could have been partially hydrolyzed into their monomers Matusek et al., (2009). As a consequence the concentration of reducing sugars in probiotic mango juices increased due to the supplementation of inulin Figure (3).

Similar results of increase in reducing sugars were reported by Yusof et al., (2000) in their storage studies of apple juice, tomato juice, pineapple juice and sugarcane juice, respectively. This is due to the conversion of inulin to reducing sugars. These results showed that the rate of conversion of inulin was affected by both storage time and type of strain. 


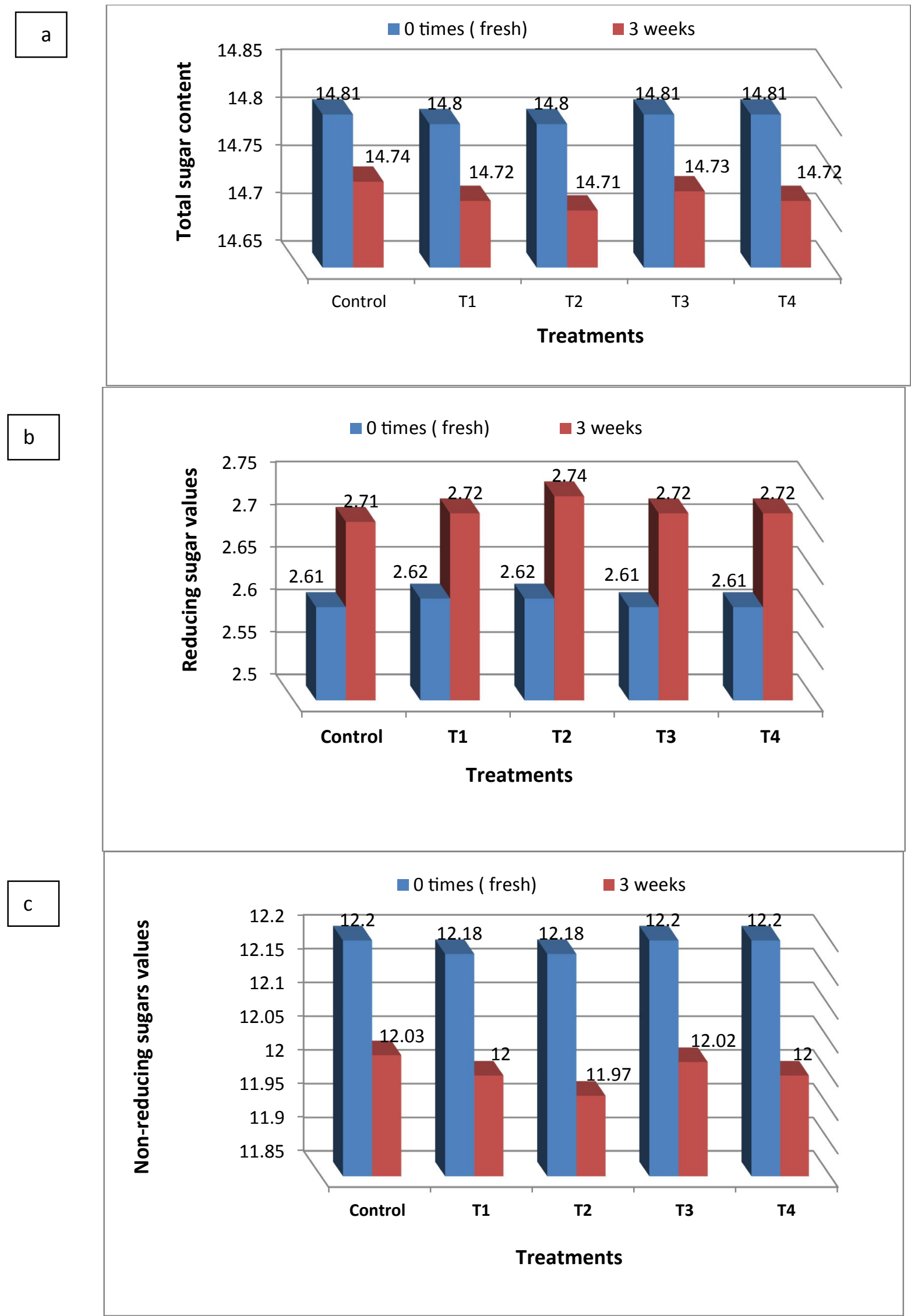

Fig 3 (a, b \&c): Total sugars, Reducing sugars and non- reducing sugars content of fresh mango juices treated with or without inulin and two different strains of probiotic ( $L b$. rhamnosus\& Bif.breve) and during storage at temp $\left(2-6 \mathrm{C}^{\circ}\right)$ for 3 weeks. 


\subsection{2- Changes in vitamin $C$ content:}

For concerning of Vit-C it's quantity in fresh mango juices (at 0 times) were (36: 37) $\mathrm{mg}$ / $100 \mathrm{ml}$ juice for control and all treated samples. While Changes in vitamin $\mathrm{C}$ content after storage 3 weeks Fig (4) showed that there are changes in the value of vitamin $C$ during storage of mango juices treated with or without inulin and different probiotic strains (Lb. rhamnosus, Bifidobacterium breve) at refrigerator temp $\left(2-6 \mathrm{C}^{\circ}\right)$.

During storage vitamin $\mathrm{C}$ had slightly reduce, the results indicate that the processing and storage of the beverages were suitable, as vitamin $\mathrm{C}$ is an unstable compound and prone to oxidation, it breaks down easily and degrades steadily during storage Kashudhan et al., (2017). Furthermore, the phenolic compounds are sensitive to oxidation when exposed to oxygen, heat, and light Porto et al., (2018). The use of glass flasks and the low storage temperature $\left(2-6^{\circ} \mathrm{C}\right)$ may have contributed to the preservation of vitamin C Miranda et al., (2019).

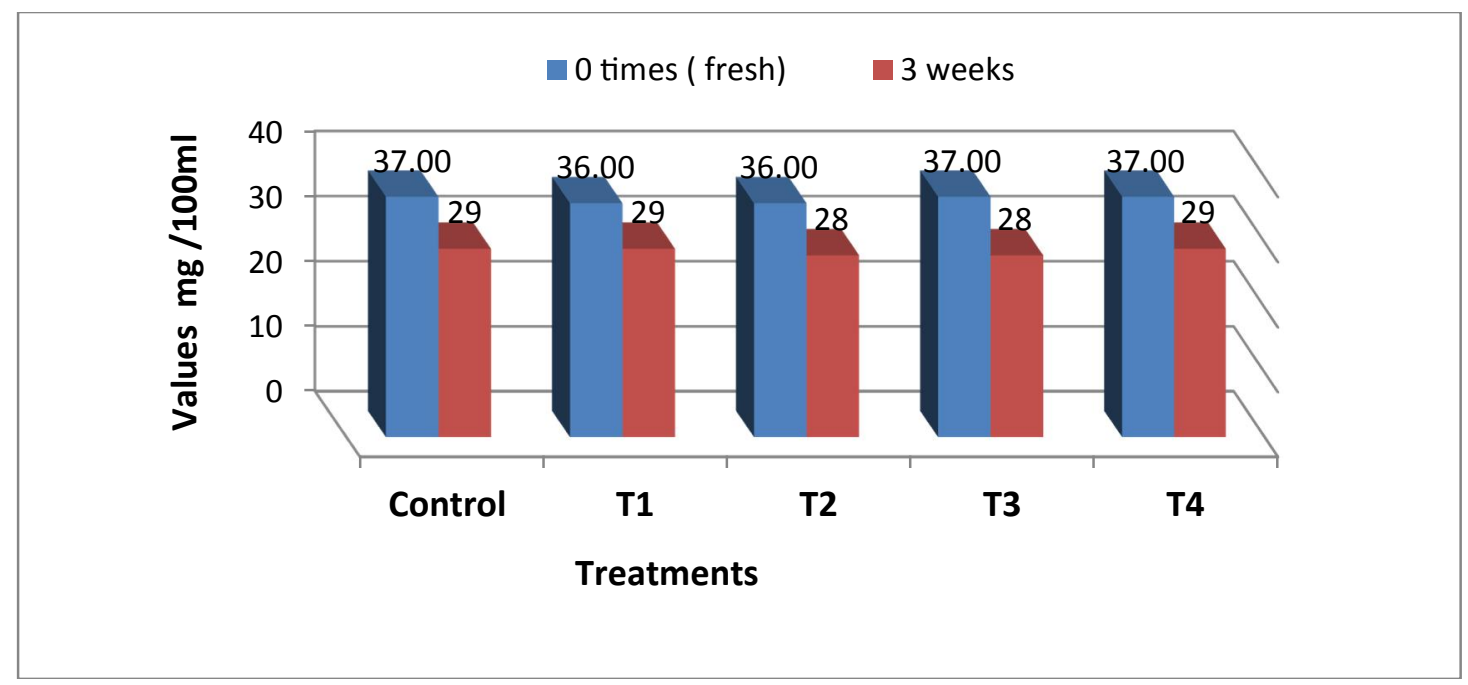

Fig. 4: Vitamin $\mathrm{C}$ content of fresh mango juices treated with or without inulin and two different strains of probiotic (Lb. rhamnosus \& Bif.breve) and during storage at temp $\left(2-6{ }^{\circ} \mathrm{C}\right)$ for 3 weeks.

\subsection{Physico-chemical analysis}

\subsubsection{Changes in $\mathrm{pH}$ and Total Titratable acidity TA \%}

$\mathrm{PH}$ is an important indicator for microbial growth and sensory quality of a juice. Figure (5) shows the changes in $\mathrm{pH}$ values and Titratable acidity of mango juice treated with or without $2 \%$ inulin and two different probiotic strains ( Lb. rhamnosus, Bifidobacterium breve) during storage (0 time, 1 week, 2 week and 3 week) at refrigerator temp $\left(2-6{ }^{\circ} \mathrm{C}\right)$.

Although, the mango juice had an initial $\mathrm{pH}$ value of 4.5 , it could be noticed from these data decreased in $\mathrm{pH}$ values of mango juice during storage in all treated samples $\mathrm{T}_{1}, \mathrm{~T}_{2}, \mathrm{~T}_{3}$ and $\mathrm{T}_{4}$ compared with the value of control in both fresh ( 0 time) and after storage for 1 week, 2 week and 3 weeks at $\left(2-6{ }^{\circ} \mathrm{C}\right)$ were as the same (4.15). The highest value of $\mathrm{pH}$ was noticed in the treated samples with $2 \%$ inulin, $\mathrm{T}_{1}$ were $4.11,3.93,3.87,3.81$ respectively, $\mathrm{T}_{3}$ were $4.13,3.96,3.85$ and 3.76 respectively, while the lowest value of $\mathrm{pH}$ was noticed in the treated samples without addition of $2 \%$ inulin. The values $\mathrm{T}_{2}$ were $4.11,3.99,3.92$, and 3.84 respectively, $\mathrm{T}_{4}$ were $4.13,3.98,3.89$ and 3.82 respectively.

These results are in agreement with those of Nualkaekul and Charalampopoulos (2011) who reported that this decrease in $\mathrm{pH}$ was likely due to the breakdown of acids.

Also, these results are in agreement with those of Mousavi et al., (2011) they mentioned that Growth of probiotic organisms in an appropriate medium contributes to the release of organic acid (lactic acid) and consequently decreases the $\mathrm{pH}$ value of the substrate.

Also, these results are consistent with Kun et al., (2008) and Panda et al., (2007) they showed that the main cause of $\mathrm{pH}$ decrease was the synthesis of organic acids (mainly lactate) by lactic acid bacteria, these compounds extend the shelf life of foods because they suppress the growth of putrefying and pathogenic bacteria. 
Figure (5) illustrated the decreased in $\mathrm{pH}$ during storage appeared to be positively correlated with the increasing TA; whereby, as lactic acid is produced the $\mathrm{pH}$ decreases and the TA increases. Values of TA in all treated samples and control at 0 time, it ranged from(0.170:0.172) \% only, after storage 3 week all treated samples and control had high values of TA it ranged from $(0.172: 0.173) \%$ only. The highest value of TA was noticed in the all treated samples with $2 \%$ inulin $\mathrm{T}_{1}$ and $\mathrm{T}_{3}$, the values were $(0.173) \%$ after 3 weeks, While the lowest value of TA was noticed in the treated samples without addition of $2 \%$ inulin $\mathrm{T}_{2}$ and $\mathrm{T}_{4}$. The values were $(0.172) \%$. This could be due to the fact that inulin enhancing the growth rate of probiotic strains as bifidogenic factor. These results are in agreement with those of Tuohy et al., (2001) they mentioned that inulin increasing population of bifidobacteria and /or lactobacillus.

Also, these results are in agreement with Pereira et al., (2018) who reported that an association of probiotic viability with the intrinsic characteristics of the beverages such as acidity. As mentioned above, in all treatments the $\mathrm{pH}$ values showed decrease reflecting the growth of bacteria and also a slight increase of the juice acidity measured as present of citric acid.

Also agreement with Tripathi and Giri, (2014) who cleared that among various probiotics, lactobacilli generally found to resist and survive in fruit juices with $\mathrm{pH}$ range from 4.3 to 3.7

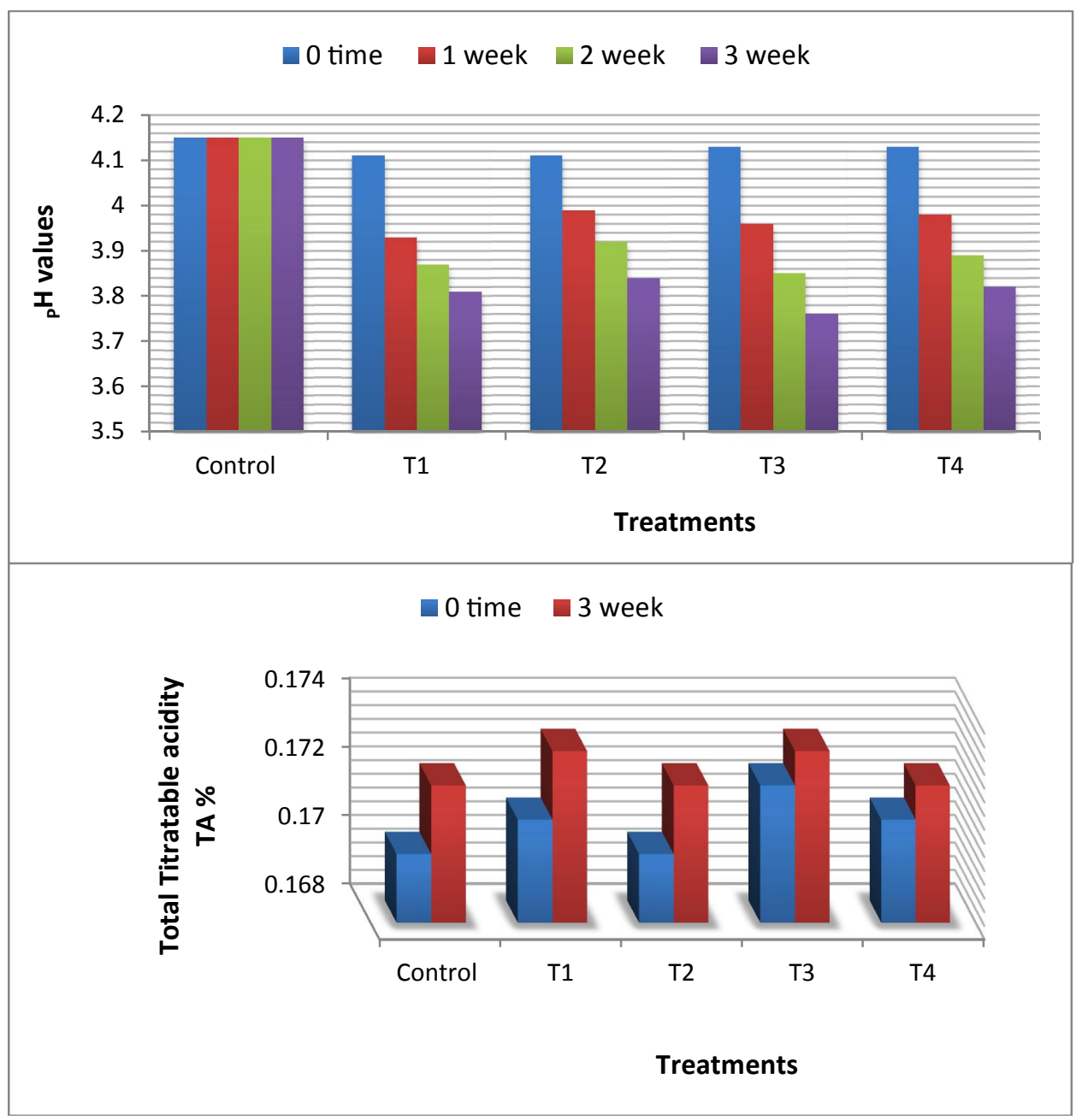

Fig. 5: Changes ${ }_{\mathrm{p}} \mathrm{H}$ and Titratable acidity of mango juice treated with or without $2 \%$ inulin and two different probiotic strains (Lb. rhamnosus, Bifidobacterium breve) during storage at refrigerator temp $\left(2-6{ }^{\circ} \mathrm{C}\right)$.

\subsubsection{Total soluble solids (TSS)}

Figure (6) illustrated the values of total soluble solids (TSS) of mango juice treated with or without $2 \%$ inulin and two different probiotic strains (Lb. rhamnosus, Bifidobacterium breve) in both fresh (0 time and after 3 weeks) at refrigerator temp $\left(2-6^{\circ} \mathrm{C}\right)$, there are no changes in the values of 
(TSS) for treated samples in both fresh and after storage for 3 weeks at $\left(2-6{ }^{\circ} \mathrm{C}\right)$. The values were as the same (12) \% only. The proliferation of Lb. rhamnosus and Bifidobacterium breve in mango juice was expected to decrease the TSS of the juice due to their sugar consumption. However, no changes were observed in the TSS of probiotic juices Figure (6).

This discrepancy is also observed by Di Cagno et al., (2011) and Koh et al., (2010) in the fermentation of mixed fruit and vegetable juice and tomato juice, respectively. Lactic acid, which is produced during the fermentation of sugars by probiotic, might be responsible for the insignificant changes of TSS. Furthermore, TSS is only an approximate measure of soluble solids, hence minor changes in the sugar and organic acid level caused by fermentation and storage may not be evident using this measurement.

Also, these results are agreement with Verma and Joshi, (2000) who showed that TSS in fruit juices is largely contributed by sugars $(90 \%-95 \%)$. However, other minor compounds, such as organic acids, pigments and amino acids in fruit juices are also involved in the measurement of TSS.

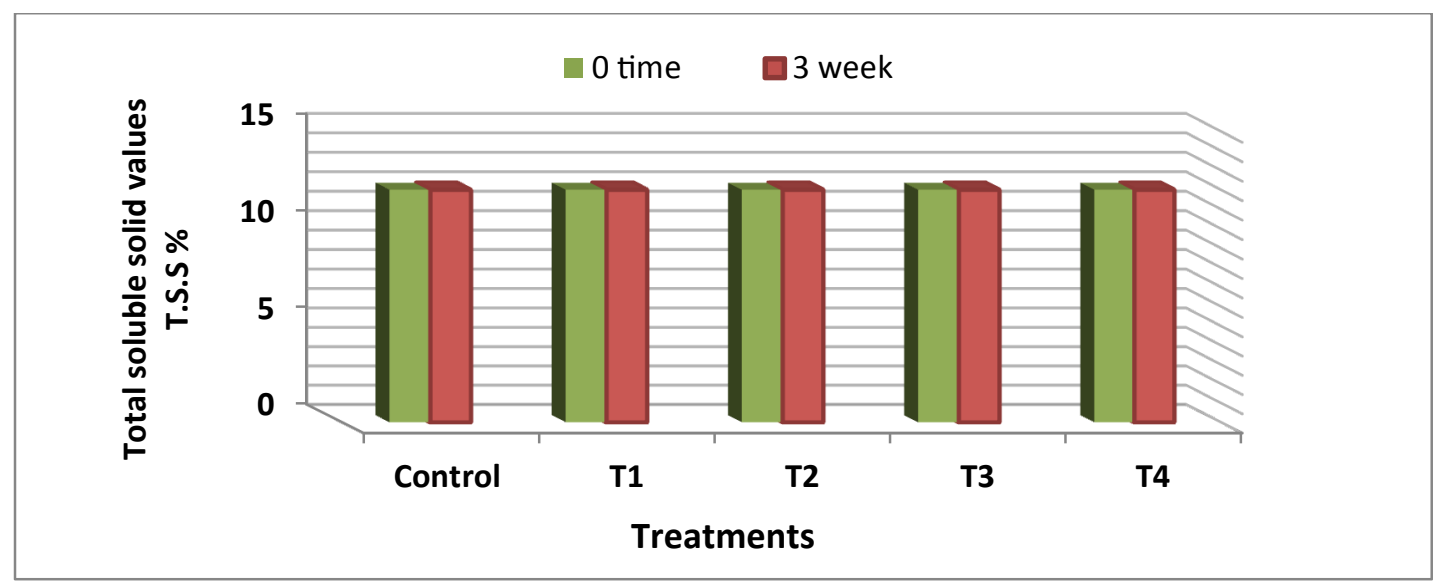

Fig. 6: Total soluble solids (TSS) of mango juice treated with or without $2 \%$ inulin and two different probiotic strains (Lb. rhamnosus, Bifidobacterium breve) during storage at refrigerator temp $\left(2-6{ }^{\circ} \mathrm{C}\right)$.

\subsection{Physical properties:}

\subsubsection{Viscosity (cps):}

Figure (7) illustrated the viscosity values of mango juice treated with or without $2 \%$ inulin and two different probiotic strains (Lb. rhamnosus, Bifidobacterium breve) in both fresh (0 time and after 3 weeks) at refrigerator temp $\left(2-6^{\circ} \mathrm{C}\right)$, It is obvious from these results that the viscosity value of $\mathrm{T}_{1}$ was (1591.2), $\mathrm{T}_{3}$ was (1584.1) at 0 times (fresh), but a significant difference was noticed between the formulation containing of this treatment $(2 \%$ inulin) with the same strains but without inulin at 0 times $T_{2}$ was (1582.9), $T_{4}$ was (1579.5) when fresh. The viscosity gradually increased throughout the storage period to reach a maximum after 3 weeks in treated samples with $2 \%$ inulin, $\mathrm{T}_{1}$ was (1592.1), $\mathrm{T}_{3}$ was (1584.9), while the lowest value was noticed in treated samples without inulin $\mathrm{T}_{1}$ and $\mathrm{T}_{3}$ $(1583.1 ; 1580.5)$ resp. It could be noticed from these data that all treatments with or without inulin had a higher viscosity when fresh and throughout the storage compared to the values of control in both fresh and after storage 3 weeks were $(1582.7 ; 1562.7)$ resp.

The results indicated that there was a significant positive relationship between viscosity and the amount of added inulin and mango juice. These results are in agreement with those reported by Debon et al., (2012) and Hekmat et al., (2015) who cleared that the apparent viscosity of the product contains inulin increased with storage time; inulin fiber is a type of prebiotic that is a low calorie sweetener and fat substitute that acts as a bulking agent. Also in agreement with the results of Islam et al., (2018) who showed that addition of mango juice may have supported to strengthen the structure; the inherently thick viscosity of the formulation may be a result of the total soluble solids content of mango juice. 


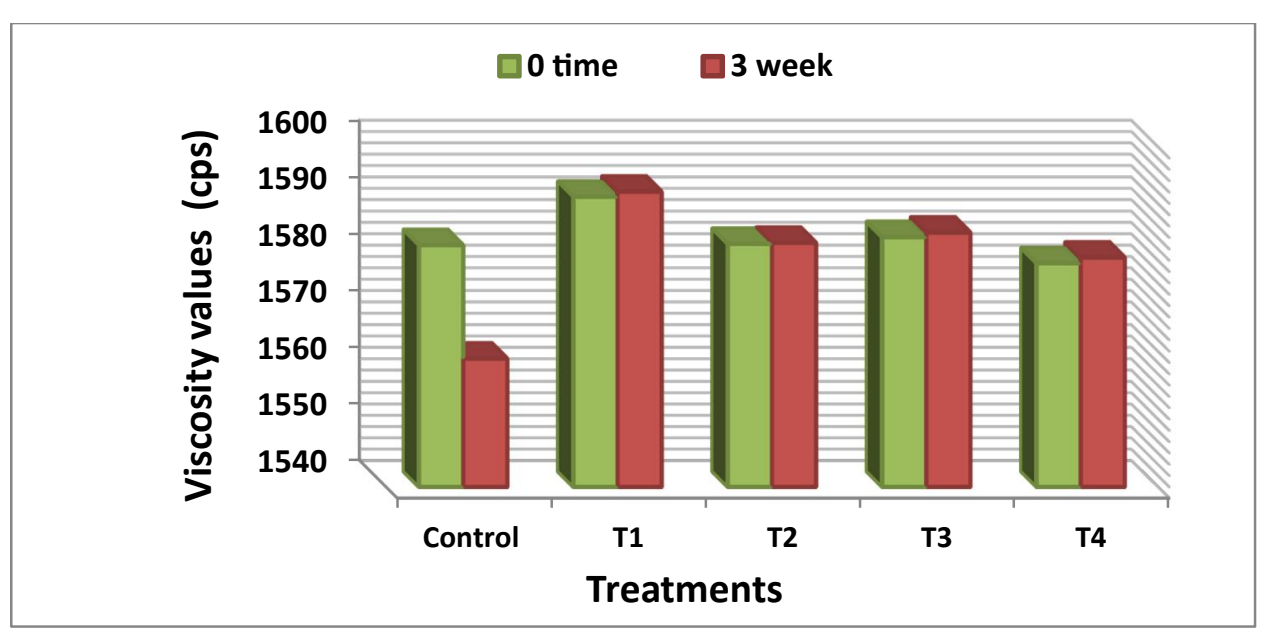

Fig. 7: Changes in the viscosity values of mango juice treated with or without $2 \%$ inulin and two different probiotic strains (Lb. rhamnosus, Bifidobacterium breve) during storage at refrigerator temp $\left(2-6^{\circ} \mathrm{C}\right)$.

Also, these results are in agreement with Costa et al., (2017) who indicated that the increasing in viscosity that detected in the fruit juices could be related to the ability of some Lactobacillus species to produce exopolysaccharides that may act as texturizing agents, increasing the viscosity of the final product and interacting with the other juice constituents (e.g., proteins).

\subsubsection{Color of Mango juices:}

Color is an important quality indicator in terms of nutritive value and attractiveness of various food products, including fruit juices during processing and storage. The color parameters of mango juice treated with or without $2 \%$ inulin and two different probiotic strains (Lb. rhamnosus, Bifidobacterium breve) during storage (0 time and after 3 week) at refrigerator temp $\left(2-6{ }^{\circ} \mathrm{C}\right)$ were measured and indicated in Table (3).

Table 3:Hunter color values of mango juice treated with or without $2 \%$ inulin and two different probiotic strains (Lb. rhamnosus, Bifidobacterium breve) during storage (0 time and after 3 weeks) at refrigerator temp (2-6 o C).

\begin{tabular}{cccccc}
\hline & \multicolumn{6}{c}{ Fresh (At 0 time) } & $\mathbf{T}_{\mathbf{3}}$ & $\mathbf{T}_{\mathbf{4}}$ \\
\hline Samples & Control & $\mathbf{T}_{\mathbf{1}}$ & $\mathbf{T}_{\mathbf{2}}$ & 61.92 & 62.17 \\
$\mathbf{L}^{*}$ & 61.69 & 61.70 & 62.77 & 11.72 & 10.75 \\
$\mathbf{a}^{*}$ & 9.25 & 12.25 & 10.71 & 58.13 & 59.96 \\
$\mathbf{b}^{*}$ & 58.60 & 59.69 & 59.71 & 0.21 & 0.18 \\
$\mathbf{a} / \mathbf{b}$ & 0.16 & 0.21 & 0.17 & 59.29 & 60.91 \\
Saturation & 59.32 & 60.93 & 60.66 & 0.09 & 0.09 \\
Hue & 0.11 & 0.08 & 0.09 & & \\
\hline & \multicolumn{7}{c}{ After (3 weeks) } & $\mathbf{T}_{\mathbf{2}}$ & $\mathbf{T _ { 3 }}$ & $\mathbf{T}_{\mathbf{4}}$ \\
Samples & Control & $\mathbf{T}_{\mathbf{1}}$ & 61.42 & 60.03 & 61.48 \\
$\mathbf{L}^{*}$ & 61.50 & 60.47 & 9.89 & 11.07 & 9.56 \\
$\mathbf{a}^{*}$ & 8.19 & 11.97 & 55.33 & 54.57 & 54.24 \\
$\mathbf{b}^{*}$ & 52.08 & 52.66 & 0.16 & 0.22 & 0.17 \\
$\mathbf{a} / \mathbf{b}$ & 0.16 & 0.23 & 56.20 & 55.68 & 55.07 \\
Saturation & 52.72 & 54 & 0.09 & 0.08 & 0.09 \\
Hue & 0.11 & 0.07 & & & \\
\hline
\end{tabular}

$* \mathbf{b}=$ Yellowness $\quad * \mathbf{L}=$ lightness $* \mathbf{a}=$ Redness.

$\mathbf{T}_{1}$ : Lb. rhamnosus +inulin, $\mathbf{T}_{2}$ : Lb. rhamnosus without inulin, $\mathbf{T}_{3}$ : Bif. breve +inulin, $\mathbf{T}_{\mathbf{4}}$ : Bif. breve without inulin.

Obviously, there was a significant difference between the parameter colors at 0 times and after 3 weeks storage. Lightness values of all treated samples and control at 0 time ranged from (61.69:62.77) only. While $T_{1}, T_{2}, T_{3}$ and $T_{4}$ were found to be lower values $(60.47,61.42,60.03$ and 
61.48 resp) than that of the control (61.50) after storage 3 weeks; we noticed that inulin and different probiotic strains (Lb. rhamnosus, Bifidobacterium breve) had influenced the color of treated samples; it contributed to slightly decrease lightness (L) parameters during storage period; it could be caused by the growth cultures of Lb. rhamnosus and Bifidobacterium breve.

These results are in agreement with El-Hatmi et al., (2018) who cleared that, in addition to milk used, the use of different starter cultures might affect the color values.

Redness (a) of all treated samples and control at 0 time ranged from $(9.25: 12.25)$ only. While redness (a) of $T_{1}, T_{2}, T_{3}$ and $T_{4}$ had redness values lower $(11.97,9.89,11.07$ and 9.56 resp) than that of the control (8.19) after storage 3 weeks.

Yellowness of all treated samples and control at 0 time ranged from (58.13:59.96) only. After 3 week Yellowness of $\mathrm{T}_{1}, \mathrm{~T}_{2}, \mathrm{~T}_{3}$ and $\mathrm{T}_{4}$ had values lower $(52.66,55.33,54.57$ and 54.24 resp) than that of the control (52.08). There was fluctuation in the other color parameters ( $a^{*}$ and $b^{*}$ ) a slight decrease in redness (a) and yellowness values in all treatments samples at the end storage period.

These results are in agreement with Pimentel et al., (2015) who reported that the color intensification in some days of storage could have been related to nonoxidative and oxidative reactions of polyphenols, resulting in colored condensation products; and to a lesser extent, by the Maillard reaction or formation of melanoidins.

Saturation values (which indicated degrees of color intensity) of all treated samples and control at 0 time ranged from (59.29:60.93) only; while the values of all treated samples $\mathrm{T}_{1}, \mathrm{~T}_{2}, \mathrm{~T} 3$ and $\mathrm{T}_{4}$ were higher values $(54,56.20,55.68$ and 55.07; respectively than that of the control (52.72) after storage 3 week.

These results are in agreement with Da Costa et al., (2017) who showed that may be related to ascorbic acid interaction with pigments of the juices, resulting in the decrease in the color intensity.

Hue angle showed the relation of hunter redness (a) and yellowness (b) color scores on a polar plan as a compared to control. The tabulated results indicated that all treated samples and control at 0 time ranged from (0.08:011) only; the values of treated samples at the end of storage $T_{1}, T_{2}, T_{3}$ and $T_{4}$ were lower values $(0.07,0.09,0.08$, and 0.09 ; respectively) than that of the control $(0.11)$, while the value of Hue angle for treated samples $\mathrm{T}_{2}$ and $\mathrm{T}_{4}$ in both fresh and after storage for 3 weeks at $\left(2-6 \mathrm{C}^{\circ}\right)$ were as the same (0.9). From the previous results it can be concluded that the effect of inulin and different probiotic strains on mango juice color was greater and noticeable.

The present result agree with the finding reported by Majchrzak et al., (2010)who reported that the changes in color values of probiotic dairy drinks during storage may result from the changes in $\mathrm{pH}$ as a result of increased acidity in the product. This is due to the growth cultures of Lb. rhamnosus \& Bifidobacterium breve.

3. Sensory evaluation:

Sensory evaluation's results of probiotic mango juice with or without inulin and different probiotic strains (Lb. rhamnosus, Bifidobacterium breve) at refrigerator temp $\left(2-6{ }^{\circ} \mathrm{C}\right)$ during storage period are presented in Figure (8).

Results of sensory characteristics for mango juice with all treatments were not differ significantly $(\mathrm{p}<0.05)$ in the color, flavor and viscosity (means $\pm \mathrm{SD})$ of probiotic mango juice as compared to control after 7 Days of storage. These results agree with Ellendersen et al., (2012) reported that a challenge for probiotic fortification of juices is product acceptance by consumers. Also all treatments were non-significant for odor as compared to each other, except $T_{3}$ treatment which had significant decrease $(3.00 \pm 0.12)$ as compared to $\mathrm{T}_{1}(3.85 \pm 0.11)$. Moreover taste scores had significant increase in treatments $T_{1}$ and $T_{2}\left(3.80 \pm 0.16\right.$ and $3.70 \pm 0.11$ respectively) as compared to $T_{3}, T_{4}$ samples $(2.6 \pm 0.13$ and $2.45 \pm 0.17$ respectively) and non-significant increase as compared to control juice (3.55 \pm 0.19$)$. Whereas overall acceptability scores had significant decrease in treatments $T_{3}$ and $\mathrm{T}_{4}\left(2.30 \pm 0.13\right.$ and $2.70 \pm 0.10$ respectively) as compared to $\mathrm{T}_{1}$ and $\mathrm{T}_{2}$ and control samples (3.95 \pm 0.12 , $3.70 \pm 0.15$ and $3.50 \pm 0.17$ respectively). From the previous results it could be notice that Bif.breve + inulin $\left(\mathrm{T}_{3}\right)$ and Bif.breve without inulin $\left(\mathrm{T}_{4}\right)$ had the lowest scores (mean $\pm \mathrm{SD}$ ) for sensory characteristics (taste and overall acceptability).

The results of sensory evaluation of different probiotic mango juice with or without inulin at refrigerator temp $\left(2-6^{\circ} \mathrm{C}\right)$ After 2 weeks of storage are presented in Figure (8) revealed that all treatments were not differ significantly $(\mathrm{p}<0.05)$ in the color and viscosity of probiotic mango juice as compared to control. 


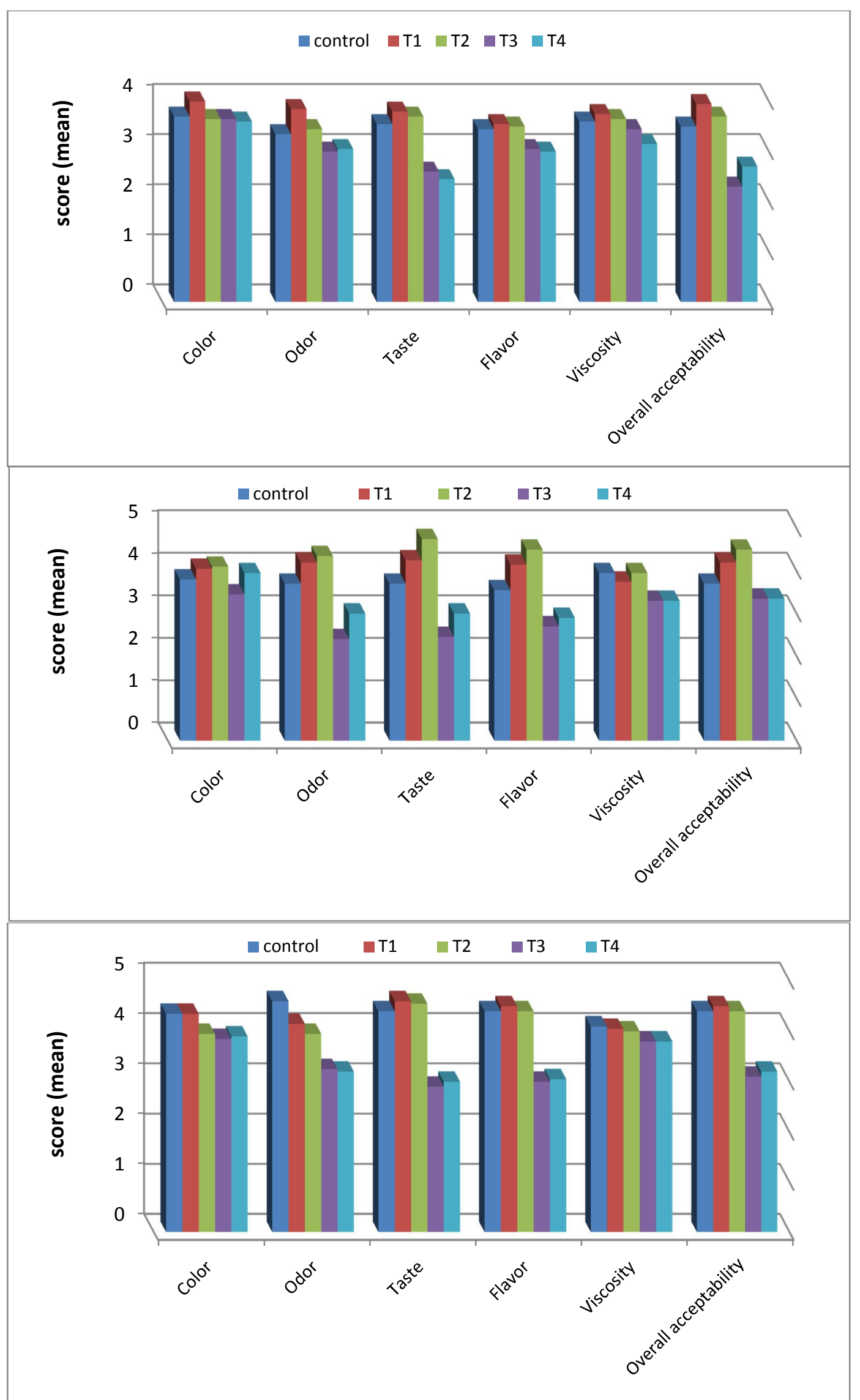

Fig. 8: Mean values of sensory characteristics of probiotic mango juice with or without inulin and different probiotic strains (Lb. rhamnosus, Bifidobacterium breve) at refrigerator temp (2-6 C). 
While Odor scores had significant increase in treatments $T_{1}$ and $T_{2}(4.20 \pm 0.13$ and $4.35 \pm 0.15)$ as compared to $\mathrm{T}_{3}$ and $\mathrm{T}_{4}(2.40 \pm 0.11$ and $3.00 \pm 0.10$ respectively) and non-significant increase as compared to control (3.70 \pm 0.10$)$.Also the same effect was noticed in taste mean scores, which had significant increase in $T_{1}$ and $T_{2}(4.25 \pm 0.14$ and $4.75 \pm 0.15)$ as compared to $T_{3}$ and $T_{4}(2.45 \pm 0.12$ and $3.00 \pm 0.1$ respectively).

The presented data of flavor mean score in previous table it could be show significant decrease in $\mathrm{T}_{3}(2.7 \pm 0.16)$ and $\mathrm{T}_{4}(2.9 \pm 0.11)$ samples as compared to control juice $(3.55 \pm 0.14), \mathrm{T}_{1}(4.15 \pm 0.16)$ and $\mathrm{T}_{2}(4.5 \pm 0.15)$. Otherwise there is increase significant in $\mathrm{T}_{2}(4.5 \pm 0.15)$ as compared to control juice. Also the same observation noticed in overall acceptability where $T_{3}(3.35 \pm 0.13)$ and $T_{4}$ (3.35 \pm 0.12$)$ had significant decrease as compared to control $(3.7 \pm 0.14), \mathrm{T}_{1}(4.2 \pm 0.12)$ and $\mathrm{T}_{2}$ (4.50 \pm 0.11$)$. Whereas all treatments were considered not poor according to degree of score sheet $(1$ represents very poor and 5 represents very good), except $T_{3}$ juice which had mean score less than 3 in both characteristics odor (2.40 \pm 0.11$)$, taste $(2.45 \pm 0.12)$ and flavor $(2.7 \pm 0.16)$ in $\mathrm{T}_{3}$ (Bif.breve +inulin).The present results agree with Cais-Sokolińska et al., (2008) who reported that the use of probiotic cultures in the production of fermented dairy drinks was effective on taste and aroma in the final product and positively affected the criteria of sensory evaluation.

However, the scores for the color and viscosity of probiotic mango juice in all treatments was found to be not significant at $\mathrm{p} \leq 0.05$ for all treatments of probiotic mango juice at the end of storage (after 3 weeks) as data presented in Table (00). Moreover the results noticed that the sensory characteristics of Taste, flavor and overall acceptability scores had significant decrease treatments $\mathrm{T}_{3}$ and $\mathrm{T}_{4}(2.90 \pm 0.11$ and $3.00 \pm 0.10) ;(3.00 \pm 0.12$ and $3.05 \pm 0.11)$ and $(3.10 \pm 0.12$ and $3.20 \pm 0.11)$ respectively as compared to control, $\mathrm{T}_{1}$ and $\mathrm{T}_{2}(4.40 \pm 0.15,4.60 \pm 0.17$ and $4.55 \pm 0.16)$; $(4.40 \pm 0.14$, $4.50 \pm 0.15$ and $4.40 \pm 0.14)$ and (4.40 $\pm 0.16,4.50 \pm 0.14$ and $4.40 \pm 0.13)$ respectively.

Also the odor mean scores had significantly decreased $(p<0.05)$ in T2 $(3.95 \pm 0.13)$, T3 (3.25 \pm 0.12$)$ and T4 (3.20 \pm 0.14$)$ when compared to than control sample (4.6 \pm 0.16$)$, but it's consider acceptable to the panelists in odor characteristic of sensory evaluation according to applied score sheet $(3=$ moderate). Therefor it could be notice that the overall acceptability for all the treatments of probiotic mango juice was very good even after 21 days of storage. Such organoleptic properties are report by Luckow et al., (2006) the addition of tropical fruit juices mango or passion fruit $(10 \% \mathrm{v} / \mathrm{v})$, might positively contribute to the aroma and flavor of the final product and might avoid the identification of probiotic off-flavors by consumers.

Also, these results agreement with Srisuvor et al., (2013) who report that inulin enhance the textural and sensory properties of the final product due to its functional characteristics

These results indicate that the addition of Lb. rhamnosus +inulin $\left(\mathrm{T}_{1}\right)$ and Lb. rhamnosus without inulin $\left(\mathrm{T}_{2}\right)$ was positively associated with increased consumer liking across all characteristics. Whereas; the addition of Bif.breve +inulin $\left(\mathrm{T}_{3}\right)$ and Bif.breve without inulin $\left(\mathrm{T}_{4}\right)$ surprisingly received there was a slight difference in the mean score characteristics compared to control, $T_{1}$ and $T_{2}$ after the period of storage. So, there was generally a correlation between increased liking and addition of $L b$. rhamnosus + inulin. The improved scores are likely to be a result of the use of $L b$. rhamnosus showed more desirable properties than B. lactis Mituniewicz-Małek et al., (2019).

\section{Conclusion}

The development of probiotic fruit juices is possible, allowing the consumption of these beneficial microorganisms by people who do not like dairy products or with intolerance or allergy to milk components. All treatments achieved a mean viable count of at least $10^{7} \mathrm{CFU} / \mathrm{ml}$ during storage period. It could be concluded that prebiotic enhance the viability of probiotics and improve gastrointestinal health, the probiotic bacteria grew well in all treatments and were capable of surviving and maintaining high viability and enhancing functional properties in the all treatments during storage period without any changes in quality attributes of fruit juices (Mango juice). 


\section{References}

Al-Sheraji, H. S., A. Ismaila, Y. M. Manap, S. Mustafa, M. R. Yusofa, and A. F. Hassana, 2013. Prebiotics as functional foods: A review. Journal of Functional Foods 5:1542 - 1553.

American Public Health Association (APHA), 1976. Compendium methods for the microbiological examination of foods. $1^{\text {st }}$ ed. by Marvin specked. Washington, DC, USA.

Amin, R., S.S. Rahman, M. Hossain, and N. Choudhury, 2018. Physicochemical and Microbiological Qualities' Assessment of Popular Bangladeshi Mango Fruit Juice. The open microbiology journal, 12:135.

Anekella, K. and V. Orsat, 2013. Optimization of microencapsulation of probiotics in raspberry juice by spray drying. LWT Food Sci Tech., 50:17-24.

AOAC, 2005. Official Methods of Analysis of AOAC International.18th Ed., AOAC International, Gaithersburg, MD, USA.

Bansal, S., M. Mangal, S.K. Sharma, and R.K. Gupta, 2016. Non-dairy Based Probiotics: A Healthy Treat for Intestine.Crit. Rev. Food Sci. Nutr, 56: 1856-1867.

Blanchette, L., D. Ray, G. Belanger, and F.S. Gauthier, 1996. Production of cottage cheese using dressing fermented by bifidobacteria.J.Dairy Sci.79:8-15.

Burton-Freeman, B. M., A.K. Sandhu, and I. Edirisinghe, 2017. Mangos and their bioactive components: Adding variety to the fruit plate for health. Food and Function 8, 3010-3032.

Cais-Sokolińska, D., D.R. Romualda and J. Pikul, 2008. Physicochemical and sensory characteristics of sheep kefir during storage. Acta Scientiarum Polonorum Technologia Alimentaria 7(2): 63 73.

Champagne, C. P., A. G. Cruz, and M. Daga, 2018. Strategies to improve the functionality of probiotics in supplements and foods. Current Opinion in Food Science 22: 160- 166.

Da Costa, G. M., J. V. de Carvalho Silva, J. D. Mingotti, C. E. Barão, S. J. Klososki, and T. Pimentel, 2017.Effect of ascorbic acid or oligofructose supplementation on L. paracasei viability, physicochemical characteristics and acceptance of probiotic orange juice. LWT - Food Science and Technology, 75: $195-201$.

Debon, J., E. S. Prudêncio, and J.C.C. Petrus, 2012. Storage stability of prebiotic fermented milk obtained from permeate resulting of the microfiltration process. LWT - Food Science and Technology 47: $96-102$.

Di Cagno, R., G. Minervini, C. G. Rizzello, M. De Angelis, and M. Gobbetti, 2011. Effect of lactic acid fermentation on antioxidant, texture, color and sensory properties of red and green smoothies. Food Microbiology, 28:1062- 1071. https://doi.org/10.1016/j.fm.2011.02.011

Ding, W.K. and N.P. Shah, 2008. Survival of free and microencapsulated probiotic bacteria in orange and apple juices. Int Food Res J 15: 219-232.

El Hatmi, H., Z. Jrada, O. Oussaiefa, W. Nasria, I. Sbissic, T. Khorchania, and L.L.S. Canabady Rochelled, 2018. Fermentation of dromedary camel (Camelus dromedarius) milk by Enterococcus faecium, Streptococcus macedonicus as a potential alternative of fermented cow milk. LWT - Food Science and Technology 90: 373 - 380.

El-Hadedy, D. and S.A. El-Nour, 2012.Identification of Staphylococcus aureus and Escherichia coli isolated from Egyptian food by conventional and molecular methods. Journal of Genetic Engineering and Biotechnology, 10(1):129-135. https://doi.org/10.1016/j.jgeb.2012.01.004

Ellendersen, L.S.N., D. Granato, B.K. Guergoletto, and G. Wosiacki, 2012. Development and sensory profile of a prebiotic beverage from apple fermented with Lactobacillus casei. Eng. Life Sci. 12: $1-11$.

Fazilah, N. F., A. B. Ariff, M. E. Khayat, L. Rios-Solis, and M. Halim, 2018. Influence of probiotics, prebiotics, synbiotics and bioactive phytochemicals on the formulation of functional yogurt. Journal of Functional Foods 48:387 - 399.

Food and Drug Administration (FDA), 2002. Bacteriological Analytical Manual. 9 ${ }^{\text {th }}$ Ed., AOAC International, Arlington, VA, USA.

Galloway, L.D. and R. Burgess, 1952. Applied Mycology and Bacteriology 3rd Edition Leonard Hill. London. pp. 54 and, 57. 
Gibson, G. R., R. Hutkins, and M. Sanders, 2017. The International Scientific Association for Probiotics and Prebiotics (ISAPP) consensus statement on the definition and scope of prebiotics. Nature Reviews Gastroenterology \&Hepatology 14: 491- 502.

Hekmat, S., K.Morgan, M. Soltani, and R. Gough, 2015. Sensory Evaluation of Locally-grown Fruit Purees and Inulin Fibre on Probiotic Yogurt in Mwanza, Tanzania and the Microbial Analysis of Probiotic Yogurt Fortified with Moringa oleifera. J. Health Popul. Nutr. 33: 60 - 67.

Hossain, M.A., M.M. Hoque, M.H. Kabir, and M. Yasin, 2019. Probiotification of Mango Juice by Lactic Acid Bacteria and Quality Assessment at Refrigerated Storage Condition. Journal of Engineering Research, Innovation and Education, 1(1):1-10.

Hunter Association Lab. Inc., 1975. Hunter colorimeter. Introduction manual.(PP.Hunter, lap.)Inc.Fairfax, VA, USA.

Islam, M., F. Akter, M. Aziz, and M. Uddin, 2018. Development of probiotic milk drinks using probiotic strain isolated from local yogurt. Fundamental and Applied Agriculture 31 .

Joseph, J. P. , 2018. Probiotic genomes: Sequencing and annotation in the past decade. International Journal of Pharmaceutical Sciences and Research 9: 1351- 1362.

Kashudhan, H., A. Dixit, and A. Upadhyay, 2017. Optimization of ingredients for the development of wheatgrass based therapeutical juice using response surface methodology (RSM). Journal of Pharmacognosy and Phytochemistry, 6(2): 338- 345.

Kaur, N. and D. P. Singh, 2017. Deciphering the consumer behaviour facets of functional foods: A literature review. Appetite, 112: $167-187$.

Koh, J. H., Y. Kim, and J. H. Oh, 2010. Chemical characterization of tomato juice fermented with Bifidobacteria. Journal of Food Science, 75: 428 - 432.

Kun, S., J.M. Rezessy-Szabó, Q.D. Nguyen, and Á. Hoschke, 2008. Changes of microbial population and some components in carrot juice during fermentation with selected Bifidobacterium strains. Process Biochem. 43:816 - 821.

Lee, P. R., C. Boo, and S. Q. Liu, 2013. Fermentation of coconut water by probiotic strains Lactobacillus acidophilus L10 and Lactobacillus casei L26. Annals of Microbiology, 63, 1441-1450. https://doi.org/10.1007/s13213-013-0607-z

Luckow, T., V. Sheehan, G. Fitzgerald, and C. Delahunty, 2006. Exposure, health information and flavour-masking strategies for improving the sensory quality of probiotic juice. Appetite 47:315-323.

Majchrzak, D., B. Lahm, and K. Dürrschmid, 2010. Conventional and probiotic yogurts differ in sensory properties but not in consumers' preferences. Journal of Sensory Studies 25: 431- 446.

Matusek, A., P. Meresz, T. K. D. Le, and F. Orsi, 2009. Effect of temperature and pH on the degradation of fructo-oligosaccharides. European Food Research and Technology, 228, 355365. https://doi.org/10.1007/s00217-008-0941-8

Miranda, R. F., M. M. de Paula, G. M. da Costa, C. E. Barão, A. C. R. da Silva, R. S. L. Raices, and T. C. Pimentel, 2019. Orange juice added with L. casei: Is there an impact of the probiotic addition methodology on the quality parameters? LWT, 106: 186 - 193.

Mituniewicz-Małek, A., D. Zielińska, and M. Ziarno, 2019. Probiotic monocultures in fermented goat milk beverages - sensory quality of final product. International Journal of Dairy Technology 72(2): $240-247$.

Mousavi, Z.E., S.M. Mousavi, S.H. Razavi, Z. Emam-Djomeh, and H. Kiani, 2011. Fermentation of pomegranate juice by probiotic lactic acid bacteria. World J Microbiol Biotechnol; 27(1):123-8.

Nadelman, P., M.B. Magno, D. Masterson, A.G. da Cruz, and L.C. Maia, 2018. Are dairy products containing probiotics beneficial for oral health? A systematic review and meta-analysis. Clinical Oral Investigations 22: $2763-2785$.

Nematollahi, A., S. Sohrabvandi, A. M. Mortazavian, and S. Jazaeri, 2016. Viability of probiotic bacteria and some chemical and sensory characteristics in cornelian cherry juice during cold storage. Electronic Journal of Biotechnology, 21: 49- 53.

Nikmaram, P., S.M. Mousavi, Z. Emam-Djomeh, H. Kiani, S.H. Razavi, 2015. Evaluation and Prediction of Metabolite Production, Antioxidant Activities, and Survival of Lactobacillus casei 431 in a Pomegranate Juice Supplemented Yogurt Drink Using Support Vector Regression. Food Sci. Biotechnol., 24, 2105-2112. 
Nualkaekul, S. and D. Charalampopoulos, 2011. Survival of Lactobacillus plantarum in model solutions and fruit juices. J. Food Microbiol. 146: 111-117.

Oliveira, S.D. P.R., P. Perego, M.N. Oliveira, and A. Converti, 2012. Growth, organic acids profile and sugar metabolism of Bifidobacterium lactis in co-culture with Streptococcus thermophilus: The inulin effect. Food Research International 48: 21 - 27.

Önal Darilmaz, D., Ş. Sönmez, and Y. Beyatli, 2019. The effects of inulin as a prebiotic supplement and the synbiotic interactions of probiotics to improve oxalate degrading activity. International journal of food science \& technology, 54(1): 121-131.

Panda, S.H., M. Parmanick, and R.C. Ray, 2007. Lactic acid fermentation of sweet potato (Ipomoea batatas L.) into pickles. J. Food Process. Preserv. 31: 83- 101.

Parkar, S.G., T.M. Trower, and D.E. Stevenson, 2013. Fecal microbial metabolism of polyphenols and its effects on human gut microbiota. Anaerobe 23: $12-19$.

Penfield, M.P. and A. M. Campbell, 1990. Shortened Cakes. In "Experimental Food Science," 3rd ed. Academic Press, Inc. San Diego, CA. pp. 452-70.

Pereira, R. N., J. A. Teixeira, A. A. Vicente, P. Cappato, M. V. da Silva Ferreira, R. da Silva Rocha and A. G. da Cruz, 2018. Osmic heating for the dairy industry: A potential technology to develop probiotic dairy foods in association with modifications of whey protein structure. Current Opinion in Food Science 22: 95 - 101.

Pimentel, T. C., G. S. Madrona, S. Garcia and S.H. Prudencio, 2015. Probiotic viability, physicochemical characteristics and acceptability during refrigerated storage of clarified apple juice supplemented with Lactobacillus paracasei ssp. paracasei and oligofructose in different package type. LWT - Food Science and Technology of Food Industry, 63(1): 415- 422.

Porto, M. R. A., V. S. Okina, T. C. Pimentel, S. Garcia and S. H. Prudencio, 2018. Beet and orange mixed juices added with Lactobacillus acidophilus. Nutrition \& Food Science, 48(1): $76-87$.

Prado, F.C., J.L. Parada, A. Pandey, and C.R. Soccol, 2008. Trends in non-dairy probiotic beverages. Food Research International, 41: 111-123.

Ramos, P. E., M. A. Cerqueira, J. A. Teixeira and A. A. Vicente, 2018. Physiological protection of probiotic microcapsules by coatings. Critical Reviews in Food Science and Nutrition 58:18641877.

Ranadheera, C. S., J. Vidanarachchi, R. Rocha, A. Cruz and S. Ajlouni, 2017. Probiotic delivery through fermentation: Dairy vs. non-dairy beverages. Fermentation 3: 67.

Sarao, L. K. and M. Arora, 2017. Probiotics, prebiotics, and microencapsulation: A review. Critical Reviews in Food Science and Nutrition 57: 344 - 371.

Shah, N. and J.B. Prajapati, 2013. Effect of carbon dioxide on sensory attributes, physico-chemical parameters and viability of Probiotic L. helveticus MTCC 5463 in fermented milk. Journal of food Science and Technology 51 (12): 3886-3893.

Shoaib, M., A. Shehzad, and O. Mukama, 2016. Inulin: properties, health benefits and food applications. Carbohydrate Polymer 147: 444- 454.

SPSS, 1986. SPSS - Pc for the IBM PC / XT computer". Version 11.0 SPSS Inc., II. U.S.A.

Srisuvor, N., N. Chinprahast, C. Prakitchaiwattana, and S. Subhimaros, 2013. Effects of inulin and polydextrose on physicochemical and sensory properties of low-fat set yoghurt with probioticcultured banana puree. LWT- Food Science and Technology 51:30 - 36.

Tripathi, M.K and S.K. Giri, 2014. Probiotic functional foods: Survival of probiotics during processing and storage. Journal of Functional Foods 9: 225-241.

Tuohy, K.M., S. Kolida, A.M. Lustenberger, and G.R. Gibson, 2001. The probiotic effects of biscuits containing partially hydrolyzed guar and fructo-oligosaccharides - a human volunteer study. $\mathrm{Br} \mathrm{J}$ Nutr. Sep; 86(3):341-8.

Verma, L. R. and V. K. Joshi, 2000. Postharvest technology of fruits and vegetables: Handling, processing, fermentation, and waste management. New Delhi, India: Indus Publishing Company.

Vieira, M. M. C. and C. L. Silva, 2014. Stability of cupuaçu (Theobroma grandiflorum) nectar during storage. International Journal of Food Studies, 3:160-174.

Vijaya Kumar, B., M. Sreedharamurthy, and O.V.S. Reddy, 2013. Physicochemical analysis of fresh and probioticated fruit juices with Lactobacillus casei. Int J ApplSci Biotechnol 1:127-131. 
Wasilewski, A., M. Zielinska, M. Storr, and J. Fichna, 2015. Beneficial effects of probiotics, prebiotics, synbiotics, and psychobiotics in inflammatory bowel disease. Inflammatory Bowel Diseases 21: $1674-1682$.

World Health Organization, 1963. International standards for drinking-water. 2nd ed., WHO, Geneva.

Yildiz, E. and T. Ozcan, 2019. Functional and textural properties of vegetable-fibre enriched yoghurt. International Journal of Dairy Technology 72: 199- 207.

Yusof, S., L.S. Shian, and A. Osman, 2000. Changes in quality of sugarcane juice upon delayed extraction and storage. Food Chem. 68: 395 - 401. 